\title{
Development of a Process Based on Coagulation of polyurethane in Aqueous So- lution for Manufacturing Leather-like Products
}

\author{
Rocco Furferi1 ${ }^{1}$ (ORCID: 0000-0001-6771-5981), Walter Sabattini² (ORCID: 0000-0002-6266-0309)
}

${ }^{1}$ Department of Industrial Engineering of Florence, University of Florence, Via di Santa Marta 3, 50139, Firenze, Italy. E-mail: rocco.furferi@unifi.it

2SA - ME Co. Ltd, Via Amalfi, 41, 59013 Montemurlo PO, Italy. E-mail: sabattiniwalter@gmail.com

Multilayer synthetic leather-like textiles are traditionally manufactured by using dimethylformamide as a diluent via polymeric polyurethane coating and coagulation processes. Unfortunately, this process has a strong environ-mental impact since it encompass a complex and polluting grinding process to separate dimethylformamide from water. Furthermore, this compound was proved harmful for both environment and textile practitioners' health. The aim of this work is to improve the state of the art in the production of leather-like fabrics through the devel-opment of an innovative process of coagulation of polyurethane in aqueous solution to replace the current highly polluting process that involves the use of dimethylformamide. The coagulation is obtained by means of an IR thermal fixing thus resulting in a completely eco compatible manufacturing process. The obtained quality of the manufactured synthetic leather, tested according to textile standards, is comparable to the one obtained by means of conventional processes.

Keywords: Leather-like, Fabrics, Manufacturing, Thermal Fixing, Polyurethane, Foaming Machine

\section{Introduction and background}

In recent years, the use of multilayer textile products obtained by coating and coagulation of polyurethane polymers (PU) faced a growing interest in many markets due to the exceptional characteristics in terms of textile "hand" and appearance, similar to natural leather [1-3].

The typical production cycle of companies producing polyurethane coatings for creating leather-like products typically foresees, in many phases, the use and consumption of a nitrogenous organic compound called Dimethylformamide (DMF) as natural solvent of polyurethane polymers. As widely recognized, DMF is the amide of dimethylamine and formic acid. Its exact name is N,N-Dimethylformamide QP and its chemical formulation is $(\mathrm{CH} 3) 2 \mathrm{NOH} \mathrm{M} .=73.10 \mathrm{CAS}$ [68-12-2] EINECS 200-679-5 EEC 616-001-00-X.

Synthetic leather fabrics, which are used both for fashion products and for technical use, are manufactured with polyurethane in solution of dimethylformamide that is coagulated with water. Unfortunately, this process has a strong environmental impact since after the textile substrate is covered with polymeric materials it is necessary to separate DMF from water by means of a complex and polluting process [4]. Moreover, the use of DMF has harmful characteristics; it has long been known to be toxic to the liver, may cause abdominal pain, constipation, nausea and vomiting, headache, weakness, dizziness, skin problems, and alcohol intolerance [5].

Other undesired properties that characterize DMF compounds are related to its physical properties: the vapours are heavier than air, so they can move at ground level and can form explosive mixtures with air. Therefore, in the event of a fire, NOx vapours can be formed. For these reasons, it is necessary that DMF does not pass through the discharge system in order to avoid soil and water contamination. Absorbent materials (General Panreac Absorbent, Kieselguhr, etc.), dry sand or soils are required to collect any leaks.

The new European Directive enacted the regulation 44/04 VOC (volatile organic compounds), thus imposing the application of the European Council Directive 2019/2020 of 20 June 2019 on the limitation of emissions of volatile organic compounds due to the use of organic solvents in certain activities and installations [6]. The new rules harmonize the previous standards 2004/42/EC and Regulations (EC) No $765 / 2008$ and (EU) No 305/2011 [7], limiting the emission of DMF from $20 \mathrm{mg} / \mathrm{Nm}^{3}$ to $2 \mathrm{mg} / \mathrm{Nm}^{3}$.

$\mathrm{Nm}^{3}$ indicates the so-called "normal cubic meter" i.e. the volume of gas that occupies a cubic meter when this gas is at a temperature of 15 degrees Celsius and a pressure of $1.013 \mathrm{bar}$. The plant costs to be handled by textile small and medium-sized enterprises for the reduction of DMF emissions are therefore significantly high and often disproportionate to the actual quality improvement of the realized product. 
Consequently, in this textile field there is an urgent need in devising methods to reduce the use of Dimethylformamide for the manufacturing of artificial leather-based products.

Accordingly, the aim of this work is to improve the state of the art in the production of leather-like fabrics through the development of an innovative process of coagulation of polyurethane in aqueous solution for replacing the current highly polluting process that involves the use of DMF. This will make it possible to obtain a product with technical characteristics close to the ones characterizing conventional leather-like products, but fully eco-friendly in nature. With this new process, the polyurethane dispersion is foamed in a watery solution to obtain a wide-ranging product (e.g. artificial leather, cleaning cloth, technical waterrepellent and thermo-insulating fabrics) with appropriate aesthetic and structural characteristics. The devised process involves the use of an infrared (IR) thermo-coagulation process, which avoids a structural collapse of the foam.

Therefore, a further innovation of the work is the development of a system that allows the layer of polyurethane foam to maintain much of the initial volume giving the finished product the honeycomb layer that gives the desired characteristics. This is possible using a thermo-coagulant, i.e. a coagulant activated (at the right time) by means of an infrared field. This will avoid the use of a strong electrolyte in the dispersion that would allow the coagulation, but would also ruin the dispersion making it practically inoperative.

\section{Materials and methods}

As mentioned above, the main aim of the proposed system is to disperse and foam the polyurethane to be layered on the textile substrate by using an aqueous solution to obtain a variegated product (synthetic leather, cleaning cloth, water repellent fabric, insulation fabric, etc.) characterized by appropriate aesthetical and structural features. A thermo-coagulation process, based on the application of IR emissions, allows maintaining much of the initial volume of the polyurethane foam thus providing the finished product a leather-like layer. Such a process is able to confer to the final product the desired characteristics without using a strong electrolyte in the dispersion. Accordingly, the main tasks of the project are:

1.Design and production of optimal raw supports to be coated

2.Design and production of optimal raw supports for the coating process

3.Coagulation of the PU dispersion, avoiding the use of DMF

4.Finishing and testing of coated fabrics

Prior to describe the new process, it is necessary to state a number of technical requirements based on the typical performance of leather-like products. In detail, artificial leather fabrics are required to meet a number of technical requirements both for the substrate and for the coated finished fabric [8]. Tab.1 lists such requirements.

\section{Tab. 1 Technical requirements for leather-like products}

\begin{tabular}{|c|c|c|}
\hline & Parameter & Target value \\
\hline \multirow{6}{*}{ Substrate Parameters } & $\begin{array}{l}\text { Color fastness to artificial light (test method ISO } 105- \\
\text { B02/94) with blue scale and range from } 1 \text { to } 8 \text { [9] }\end{array}$ & $7-8$ \\
\hline & Color fastness with gray scale range from 1 to 5 [9] & 5 \\
\hline & $\begin{array}{l}\text { Color fastness to perspiration (test method ISO 105- } \\
\text { E04/94) with gray scale range } 1 \text { to } 5 \text { [10] }\end{array}$ & $\begin{array}{l}5 \text { acidic } \\
5 \text { alkaline }\end{array}$ \\
\hline & $\begin{array}{l}\text { Color fastness to washing (test method } 105-\mathrm{C} 10: 2006) \\
\text { with gray scale range from } 1 \text { to } 5 \text { [11] }\end{array}$ & 5 \\
\hline & $\begin{array}{l}\text { Color fastness to rubbing (test method ISO } 105 \mathrm{X} 12 / 01) \\
\text { with gray scale range from } 1 \text { to } 5 \text { [12] }\end{array}$ & $\begin{array}{l}5 \text { acidic } \\
5 \text { alkaline }\end{array}$ \\
\hline & $\begin{array}{c}\text { Color fastness to washing in water (test method ISO } \\
105-\mathrm{E} 01 / 94) \text { with gray scale range } 1 \text { to } 5[13]\end{array}$ & 5 \\
\hline \multirow{5}{*}{$\begin{array}{l}\text { Coated fabric Parame- } \\
\text { ters }\end{array}$} & Thermal resistance [14] & $0.020-0.030 \mathrm{~W} / \mathrm{mK}$ \\
\hline & Dimensional stability [15] & $0.5 \%-3.0 \%$ \\
\hline & Resistance to abrasion [16] & $250 \mathrm{~g} / \mathrm{cm} 2$ \\
\hline & Mean tensile stress [17] & $>118 \mathrm{~N}$ \\
\hline & Elongation [17] & $>2 \%$ \\
\hline
\end{tabular}

\subsection{Design and production of optimal raw supports to be coated}

A collection of 10 different types of fabrics (see Tab.2) each distinguished by a different blend (i.e. different composition) has been developed as a support material for the polyurethane coating process to improve the proposed process. As one of the main goals of the project is to make fabrics as environmentally friendly as possible, the blends are ideally made of cotton blended with low polyester (for technical fabrics) or linen/cotton percentages (for fabrics to be used in clothing and handbags). 
Tab. 2 Fabrics used as a support for the coating process

\begin{tabular}{|c|c|c|c|c|c|c|c|}
\hline Fabric Name & Composition & $\begin{array}{c}\text { Warp } \\
\mathbf{w i r e s} \\
\mathbf{( N} / \mathbf{c m})\end{array}$ & $\begin{array}{c}\text { Warp } \\
\mathbf{c o u n t} \\
\mathbf{( m / g )}\end{array}$ & $\begin{array}{c}\text { Weft } \\
\mathbf{w i r e s} \\
\mathbf{( N} / \mathbf{c m})\end{array}$ & $\begin{array}{c}\text { Weft } \\
\mathbf{c o u n t} \\
\mathbf{( m / g )}\end{array}$ & $\begin{array}{c}\text { Fabric } \\
\text { linear } \\
\mathbf{W e i g h t} \\
\mathbf{( g / m})\end{array}$ & $\begin{array}{c}\text { Fabric } \\
\text { Height } \\
\mathbf{( c m})\end{array}$ \\
\hline Kos Wash & $100 \%$ cotton & 44 & 11.8 & 25 & 16 & 375 & 160 \\
\hline Cover Cot & $100 \%$ cotton & 85 & 29.6 & 41 & $60 / 1$ & 230 & 160 \\
\hline Scamosciato & $\begin{array}{c}94 \% \text { cotton } 6 \% \text { poly- } \\
\text { ester }\end{array}$ & 23 & 9.5 & 39 & 12 & 530 & 178 \\
\hline $\begin{array}{c}\text { Stuoia fiam- } \\
\text { mata }\end{array}$ & $100 \%$ cotton & 32 & 7.1 & 12 & 5.4 & 500 & 160 \\
\hline Popeline $50 / 50$ & $100 \%$ cotton & 57 & 29.6 & 32 & $50 / 1$ & 185 & 160 \\
\hline $\begin{array}{c}\text { Nattè Ecolog- } \\
\text { ico }\end{array}$ & $\begin{array}{c}55 \% \text { linen, } 45 \% \text { cot- } \\
\text { ton }\end{array}$ & 40 & 11.8 & 26 & 26 & 360 & 160 \\
\hline Twill Ecologico & $\begin{array}{c}55 \% \text { linen, } 45 \% \text { cot- } \\
\text { ton }\end{array}$ & 40 & 11.8 & 25 & 26 & 350 & 160 \\
\hline Linone & $100 \%$ linen & 21 & 8.9 & 16 & $1 / 15$ & 415 & 162 \\
\hline Tela Lino & $100 \%$ linen & 20 & 19.5 & 23 & 39 & 200 & 160 \\
\hline Drill Cotone & $100 \%$ cotton & 52 & 11.8 & 22 & 20 & 405 & 160 \\
\hline
\end{tabular}

2.2 Design and production of optimal raw supports for the coating process

Before the support undergoes the innovative coating process a series of treatments are required. First, the fibers emerging from the fabric surface are burned by sliding the fabric, tangentially, under a flame (gasair mixture varying in the range $30-35 \%$ and flame temperature equal to about $950{ }^{\circ} \mathrm{C}$ ) with a speed of 80 $\mathrm{m} / \mathrm{min}$. Setting parameters used for the burning process are in Tab. 3.

Afterwards, the fabric is processed by means of an enzymatic desizing with amylases, washed using an industrial washing machine and whitened by bleaching soda treatments. Finally, the fabric is dried into a stenter with a working temperature of $120 / 130^{\circ} \mathrm{C}$ and then pre-shrunk.

Tab. 3 Burning process parameters

\begin{tabular}{|c|c|}
\hline Parameter & Settings \\
\hline Distance of the fabric from the visible flame tip & $2-3 \mathrm{~mm}$ \\
\hline Fabric flow speed & $80 \mathrm{~m} / \mathrm{min}$ \\
\hline Air-gas mixture & $30-35 \%$ \\
\hline Type of burn & Tangential \\
\hline Value of Be (Baumé) degrees [7] & $18{ }^{\circ} \mathrm{Be}$ \\
\hline Cotton-based concentration values & $30^{\circ} \mathrm{Be}$ at $14^{\circ} \mathrm{C}$ \\
\hline Concentration values of cotton rayon viscose blend & $14^{\circ} \mathrm{Be}$ at $20^{\circ} \mathrm{C}$ \\
\hline
\end{tabular}

Tab. 4 Textile substrate parameters

\begin{tabular}{|c|c|c|}
\hline Parameter & Measured Value & Delta [\%] \\
\hline $\begin{array}{l}\text { Color fastness to artificial light (test method ISO } 105-\mathrm{B} 02 / 94) \text { with blue } \\
\text { scale and range from } 1 \text { to } 8\end{array}$ & 7 & $0-6 \%$ \\
\hline Color fastness with gray scale range from 1 to 5 & 5 & $0 \%$ \\
\hline $\begin{array}{l}\text { Color fastness to perspiration (test method ISO 105-E04/94) with gray } \\
\text { scale range } 1 \text { to } 5\end{array}$ & $\begin{array}{l}5 \text { acidic } \\
4.5 \text { alkaline }\end{array}$ & $5 \%$ \\
\hline $\begin{array}{c}\text { Color fastness to washing (test method ISO 105-C01/89) with gray scale } \\
\text { range from } 1 \text { to } 5\end{array}$ & 5 & $0 \%$ \\
\hline $\begin{array}{l}\text { Color fastness to rubbing (test method ISO } 105 \mathrm{X} 12 / 01) \text { with gray scale } \\
\text { range from } 1 \text { to } 5\end{array}$ & $\begin{array}{l}\text { Moist } 4.5 \\
\text { Dry } 5\end{array}$ & $5 \%$ \\
\hline $\begin{array}{l}\text { Color fastness to washing in water (test method ISO 105-E01/94) with } \\
\text { gray scale range } 1 \text { to } 5\end{array}$ & 4.5 & $10 \%$ \\
\hline
\end{tabular}

The technical characteristics of the manufactured supports are assessed through a series of laboratory tests to assess their compliance with the expected technical requirements. Results of the experimental characterization, listed in Tab. 3, demonstrated that the textile substrate is adequate for the subsequent coating process since its properties are in-line with the values for similar substrates typically used for leather- 
like products (target value in Tab. 4).

\subsection{Coating process}

Polyurethanes in aqueous dispersion are available on the market [18], but the main obstacle to their use in artificial leather coating processes is their high stability, so that the normal coagulants, used for other types of dispersion, did not allow obtaining the desired result in the desired time. To overcome these issues, it was necessary to perform the following preliminary steps: a) Selection of a category of polyurethane that allows an aqueous dispersion according to the physical characteristics of resilience, elasticity, rigidity, flexibility, transparency, colour and elongation at break. Among the several available polyurethane typologies, the Witcobond 374-13 [19], an aliphatic polyester anionic polyurethane dispersion with no free isocyanate, proved to be the most effective in terms of resilience, transparency and resistance. Its properties are in Tab. 5.

Tab. 5 Witcobond 374-13 properties

\begin{tabular}{|c|c|}
\hline Parameter & Value \\
\hline Solids Content $(\%)$ & $59-61$ \\
\hline $\mathrm{pH}$ at $25^{\circ} \mathrm{C}$ & $7-9$ \\
\hline Viscosity at $25^{\circ} \mathrm{C}(\mathrm{mPa} \bullet \mathrm{s})$ & $50-400$ \\
\hline Polyurethane Dispersion Type & Aliphatic, polyester, anionic \\
\hline Specific Gravity at $25^{\circ} \mathrm{C}$ & 1.07 \\
\hline
\end{tabular}

b) Selection of mineral or vegetal filler, of foaming surfactants and crosslinking agents. The addition of a mineral or vegetal filler, by increasing the solid content (i.e., the concentration of dispersed and/or dissolved solid material in the polyurethane -water mixing) promotes the coagulation; however, too much mineral filler cannot be used because it alters the characteristics of the final product. Therefore, to sufficiently unstabilize the polyurethane in aqueous dispersion, at least one Cobalt sulfide $(\mathrm{CoS})$ is added. As widely recognized, $\mathrm{CoS}$ is a non-volatile organic compound (with a melting point greater than $125^{\circ} \mathrm{C}$ ), whose solubility is greater than $1000 \mathrm{~g} / 1$ at $20^{\circ} \mathrm{C}$. Among the many compounds suitable for this purpose, sucrose is preferred because of its high availability at low cost and/or low environmental impact. The CoS, by increasing the dry concentration, facilitates the subsequent coagulation of PU and, given its high solubility, during the various washings to which the semi-finished composite material is subjected, it is removed from the coagulated layer, resulting in the formation of a microporous structure. In addition to the coagulant, an acid dissociating compound is also used. It consists of a salt with high ionic dissociation in water and capable of producing a $\mathrm{pH}$ decrease to values between 3 and 6 when subjected to temperatures greater than $100^{\circ} \mathrm{C}$. Ammonium salts such as $\mathrm{NH} 4 \mathrm{Cl}$ or (NH4)2SO4 can be used for this purpose. The mix is completed by adding foaming surfactants such as sodium sulfosuccinate, sodium lauryl sulfate, sodium oleate, potassium oleate, ammonium stearate, or their mixtures. For the devised process, they are added to the mixture at a mass fraction ranging from 2.5 to $5 \mathrm{wt} \%$. Finally, crosslinking agents are added to the mixture. In the devised system, melamine/formaldehyde resins, carbodiimides, polyacrylamide resins, epoxy resins can be used. Melamine/formaldehyde resins are preferred and commercially available and therefore represent the best choice; the used amounts is equal to a mass fraction of $3 \mathrm{wt} \%$ (percentage by weight) of the total mixture. Once the compound is created with the proper mix of elements, it is possible to process it. The first process, carried out by using a micronizer (see Figure 1) consists of reducing its granulometry size from the initial $300-400 \mu \mathrm{m}$ to $30-70 \mu \mathrm{m}$, which is a more appropriate size for performing the subsequent coating process.

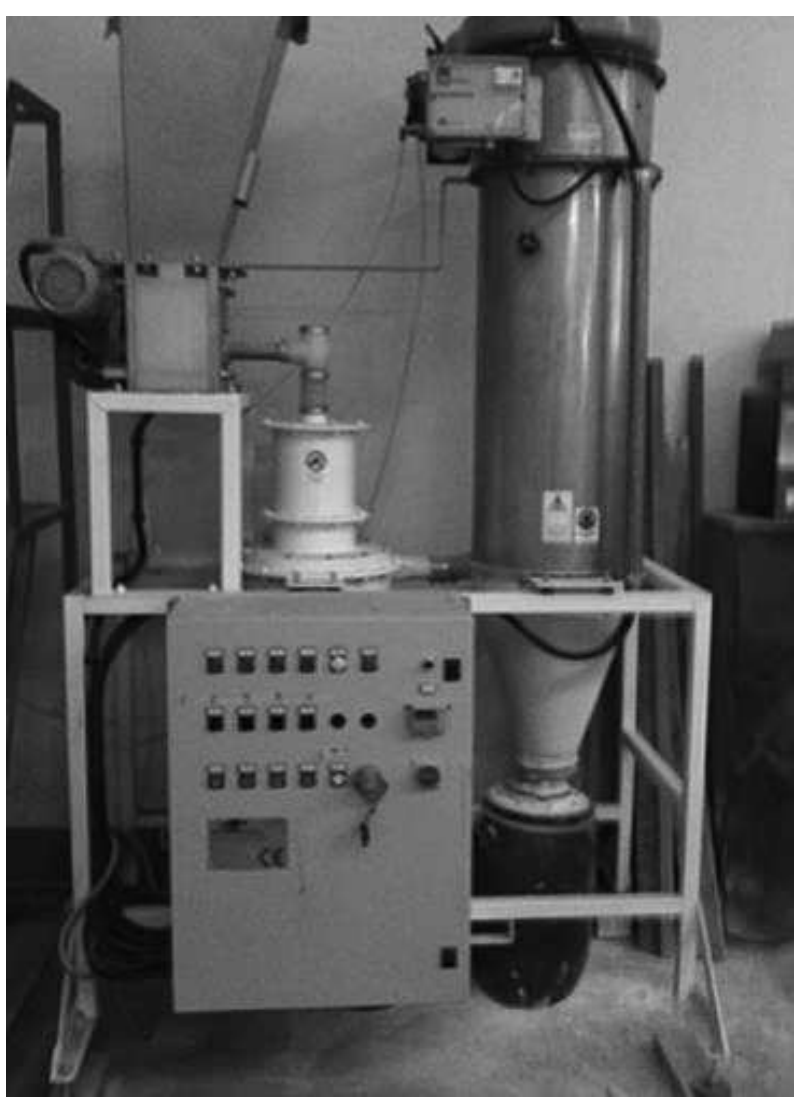

Fig.1Microniz̧er 
The micronized powder is then sent to a foaming machine (depicted in Fig. 2) together with water and air. The foaming machine has been appositely devised to obtain a foam with a density of $120 \mathrm{~g} / \mathrm{l}$. It consists of cylinder (volume equal to $0.254 \mathrm{~m} 3$ ) equipped with water and air inlet channels and a rotating auger to produce foam.

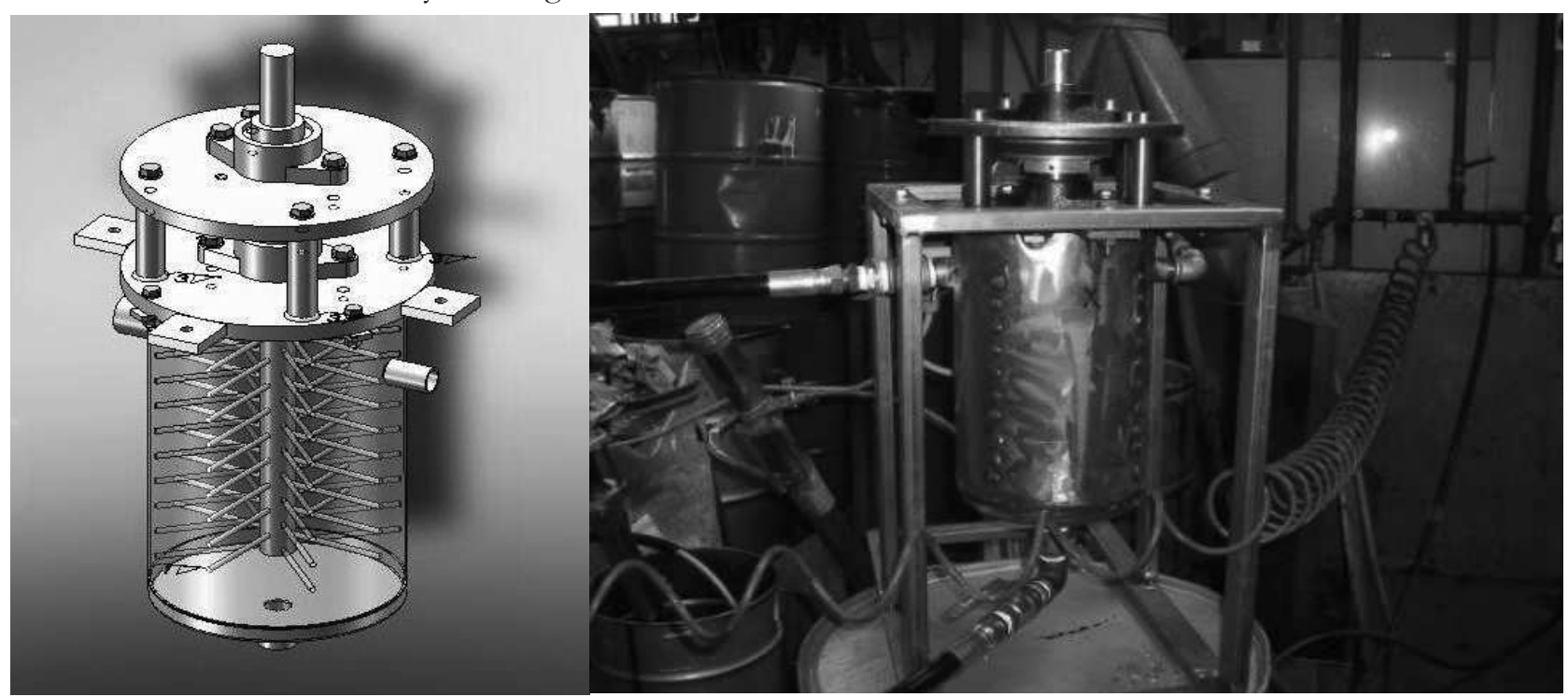

Fig.2 Foaming machine

The weight of the PU and added products is equal to $50 \mathrm{~kg}$ with a density of $200 \mathrm{~kg} / \mathrm{m}^{3}$. On the basis of technicians knowledge, the foam is required to have a density of around $205 \mathrm{~g} / \mathrm{l}$ and the expected expansion coefficient is equal to 1.1:1. To this aim, the foam is required to be composed by about $8 \%$ of air. Therefore, the main issue is to detect the optimal rotational speed of the auger to obtain the desired foam density. First, it is necessary to evaluate the optimal inlet air pressure to be sent into the cylinder. Tests were performed by varying the pressure in the range 1-6 bar, with a step equal to $0.5 \mathrm{bar}$ and constant rotational speed equal to $31.5 \mathrm{rad} / \mathrm{s}$ and airflow equal to $30 \mathrm{~g} / \mathrm{s}$.

Results (see Fig. 3a) of an interpolation of measured data shows that the higher percentage of air absorbed by the mixture (i.e. $7 \%$ ) can be obtained when the pressure is equal to $3.2 \mathrm{Bar}$. Good results are also achievable using a pressure varying in the range 3-3.5 bar. In this work, a 3 bar pressure was selected. Therefore, using air at such a pressure, the rotational speed was varied in the range $15.8-68 \mathrm{rad} / \mathrm{s}$ with a step equal to $5.3 \mathrm{rad} / \mathrm{s}$. Finally, as depicted in Fig. 3b, the optimal rotational speed for obtaining a quantity of air equal to $8 \%$ of air is equal to roughly $34.8 \mathrm{rad} / \mathrm{s}$. The mixing process, which allows mixing $0.236 \mathrm{~m}^{3}$ of PU (plus additive materials) with $0.088 \mathrm{~m}^{3}$ of air, lasts 2 min. The obtained foam density is equal to $204.4 \mathrm{~g} / 1$ and the expansion coefficient is 1.08:1.

Subsequently, the mixture polyurethane-water feeds a blade coating machine (see Fig. 4a) by means of a flexible pipe. This machine allows the support coating by providing a uniform layer ( $2 \mathrm{~mm}$ thickness) of polyurethane. It is important to highlight that, despite the special composition of the mixture, the above described process still does not allow a proper coagulation without the use of DMF. Moreover, although the polyurethane coagulates (with an extremely "slow" chemical process) the coating is water-soluble and so it may results unsuitable for technical applications.

Accordingly, in order to consolidate the coagulation, the coated fabric passes through a stenter equipped with IR lamps (Fig. 4b). The infrared illumination affords both the coating drying and a polymerization thus providing an "indissoluble" grid. In particular, the coated fabric enters under a distributor of powders where it receives $30-40 \mathrm{gr} / \mathrm{m}$ of sodium sulfate with a particle size between 30 and $70 \mu \mathrm{m}$; then, the semi-finished product passes under a $6 \mathrm{~m}$ long area where IR lamps are placed in order to allow a first coagulation. The fabric crosses the IR-illuminated area for $40 \mathrm{~s}$, therefore the fabric has a linear speed equal to $10 \mathrm{~m} / \mathrm{s}$. For this particular application, IR lamps with $0.35 \mathrm{~W} / \mathrm{mm}$ of maximum density of nominal power are used. Radiation peak of the lamps is in the range $2.2-3.2 \mu \mathrm{m}$ which is particularly suitable for the fast heating of surface parts or thin thickness materials.

Afterwards, the fabrics processed with a stenter where the final coagulation, together with drying and cross-linking of the polymer, take place. Temperature in the stenter is maintained equal to $150^{\circ} \mathrm{C}$ for the entire process. Drying duration is equal to $120 \mathrm{~s}$ while reticulation lasts $60 \mathrm{~s}$.

Eventually, the fabric is wrapped on a roller. Once the new type of coated fabrics manufactured, it is washed in order to remove possible impurities. 
This phase, carried out by using a washing machine (see Fig. 5a), allows to eliminate surfactants, sucrose and sodium sulfate. After washing, the fabric is dried again and further processing such as printing and embossing can be made. Fig. $5 \mathrm{~b}$ shows some examples of obtained leather-like fabrics.

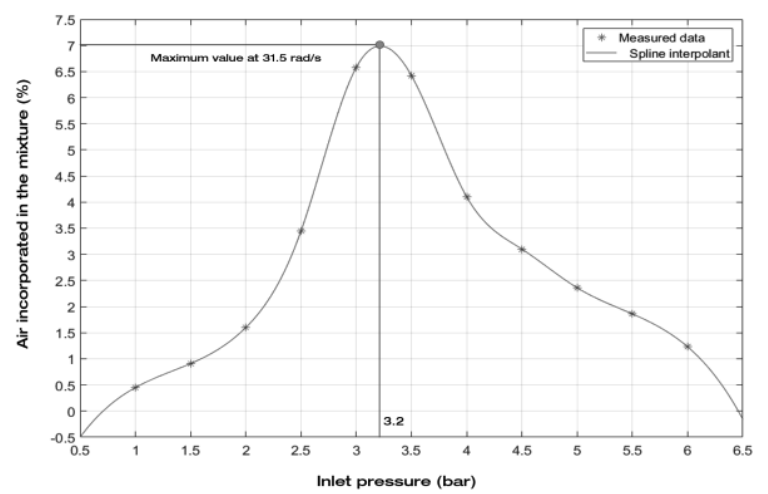

a)

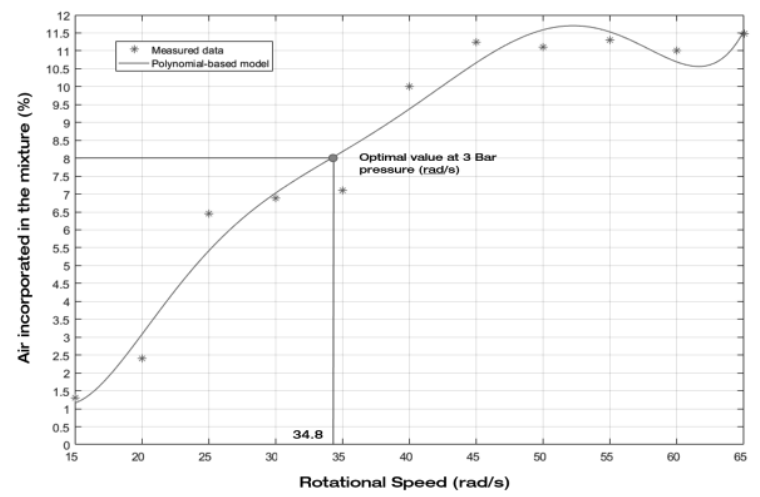

b)

Fig. 3 a) air incorporated in the mixture vs. Inlet pressure at 300 RPM rotational speed; b) air incorporated in the mixture vs. Rotational speed at 3 Bar pressure.

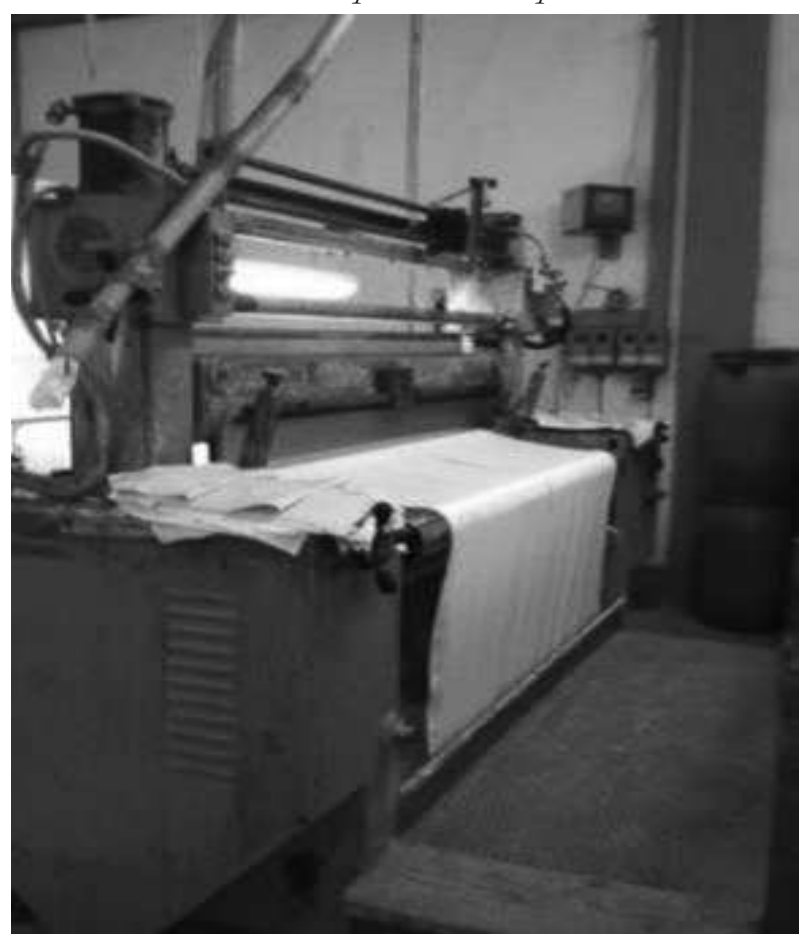

a)

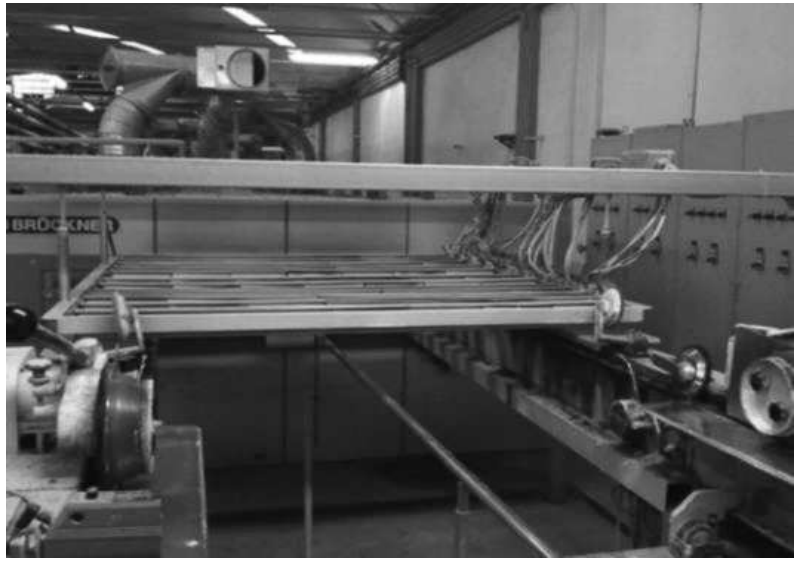

b)

Fig. 4 a) blade coating machine; b) stenter equipped with IR lamps.

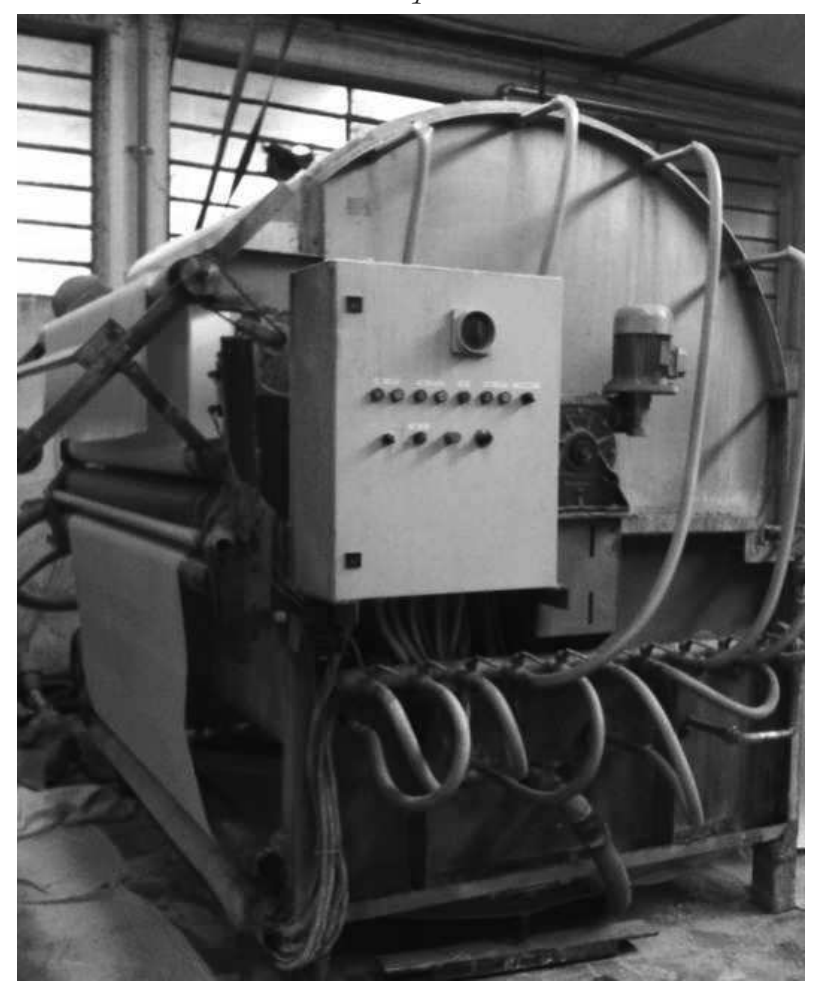

a)

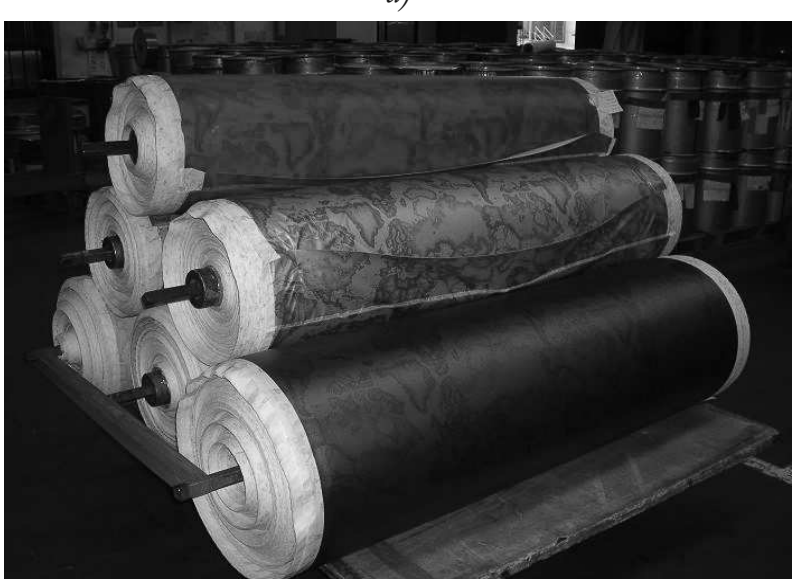

b)

Fig. 5 a) Washing machine; b) some examples of leather-like products obtained by means of the devised system 


\section{Results}

Ten prototypes, one for each substrate depicted in Tab. 2 were manufactured with the developed system. These were tested to verify their actual compliance with the technical requirements typically stated for artificial leather products. In detail, the following tests have been carried out to prove the effectiveness of the prototypes created using the DMF-free process.

\subsection{Thermal resistance}

Thermal resistance $R$ is the ratio between the absolute temperature difference $\Delta T$ between the two faces of the insulating material (i.e. the fabric) and the amount of thermal energy transferred in the unit of time (thermal flow $\phi$ ) through the unit of surface $d$ [20]. Thermal resistance in fabrics can be measured in $\mathrm{W} / \mathrm{m} \cdot \mathrm{K}$ This parameter is certainly one of the most interesting for the coated fabrics manufactured with the new method. Tested specimens proved to have similar characteristics with respect to typical leatherlike coated fabrics, as shown in Tab. 6 (showed results are related to four up to the ten prototypes, namely Kos Wash, Cover Cot, Scamosciato and Stuoia fiammata). For all the prototypes, the mean value of thermal resistance is $0.030 \mathrm{~W} / \mathrm{m} \cdot \mathrm{K}$ with a standard deviation equal to 0.005 .

\subsection{Dimensional Stability}

As required by UNI EN 1606:2013 standard, the new polyurethane formulation should undergo a dimensional stability test consisting of the determination of the increase in deformation of a foam specimen kept under a constant load, under specific conditions of temperature, humidity and time [21]. The purpose of the test is to define an admissible load for a practical application of the insulating material by evaluating its long-term behavior. Under operating conditions with constant loads within $10-15 \%$ of the compressive strength, the percentage deformations of the thickness are kept within irrelevant values (less than $2 \%$ ) for all specimens, as depicted in Tab. 6 for the four above considered prototypes. For the whole set of prototypes the mean value of dimensional stability results equal to $2.52 \%$ with a standard deviation equal to 0.56 .

\subsection{Resistance to abrasion}

It is necessary to test the various polyurethanecoated surfaces for resistance to abrasion caused by brushes, sponges, or other materials. Abrasion tools that produce micro-damage on the surfaces by repeated rubbing and scraping under controlled conditions optimally simulate the daily conditions of wear and tear. The Branca abrasion test [22] is carried out by subjecting a test sample to the action of a nylon brush under the pressure of a specified weight and a specified number of alternating cycles. Results of test for the four considered test cases are in Tab. 6. For the whole set of prototypes the mean value of this parameter results equal to $256.5 \mathrm{~g} / \mathrm{cm}^{2}$ with a standard deviation equal to 47.5 .

Tab. 6Thermal resistance, Dimensional stability and resistance to abrasion

\begin{tabular}{|c|c|c|c|}
\hline Prototype & Thermal resistance & Dimensional stability & Resistance to abrasion \\
\hline Kos Wash & $0.025 \mathrm{~W} / \mathrm{m} \cdot \mathrm{K}$ & $2.0 \%$ & $300 \mathrm{~g} / \mathrm{cm}^{2}$ \\
\hline Cover Cot & $0.027 \mathrm{~W} / \mathrm{m} \cdot \mathrm{K}$ & $1.5 \%$ & $270 \mathrm{~g} / \mathrm{cm}^{2}$ \\
\hline Scamosciato & $0.032 \mathrm{~W} / \mathrm{m} \cdot \mathrm{K}$ & $2.5 \%$ & $280 \mathrm{~g} / \mathrm{cm}^{2}$ \\
\hline Stuoia fiammata & $0.035 \mathrm{~W} / \mathrm{m} \cdot \mathrm{K}$ & $3.0 \%$ & $250 \mathrm{~g} / \mathrm{cm}^{2}$ \\
\hline
\end{tabular}

\subsection{Mechanical strength}

Tensile strength of a yarn or fabric is defined as a maximum load that it will endure without breaking when subjected to uniaxial tensile loading [23]. In this work, mechanical strength is measured according to ASTM D5034 standard [17]. Results for the four selected prototypes are in Tab 7. For the whole set of prototypes the mean value of this parameter results equal to $61.1 \mathrm{~N}$ with a standard deviation equal to 18.5 .

\section{Conclusions}

Today, sustainable development and reduction of the environmental impact are issues that textile companies have to take into account in order to remain competitive in the future market since they represent a key issue for further development of innovative products. In particular, there is today a change in attitude that involves a transition from the concept of "environment as an issue" to the one of "environment as a possibility" [24]. With the proposed method, it is possible to produce eco-compatible avoiding the use of DMF and resulting in new ecological fabrics characterized by a very high quality. The results showed that the performance of all prototypes made with the new system is comparable to that of those made with the traditional method. The process, involving both the use of a number of compounds used to facilitate the coagulation of the aqueous solution of $\mathrm{PU}$ and the use of IR for accelerating the coating procedure [25] involves a higher cost, when compared to a similar traditional facility, estimated at $2 \%$ more. This cost is mainly due to the slight increase of energetic costs to keep IR lamps operative during the entire coagulation process. The new process, on the other hand, has the 
significant advantage of not requiring DMF. Therefore, since on the Company that tested the process an entire production line, out of four, has been converted to this new process, there is a $25 \%$ saving in the emission of this compound into the wastewater to be treated and a similar reduction in emissions into the atmosphere.

Tab. 7 Mechanical Strength

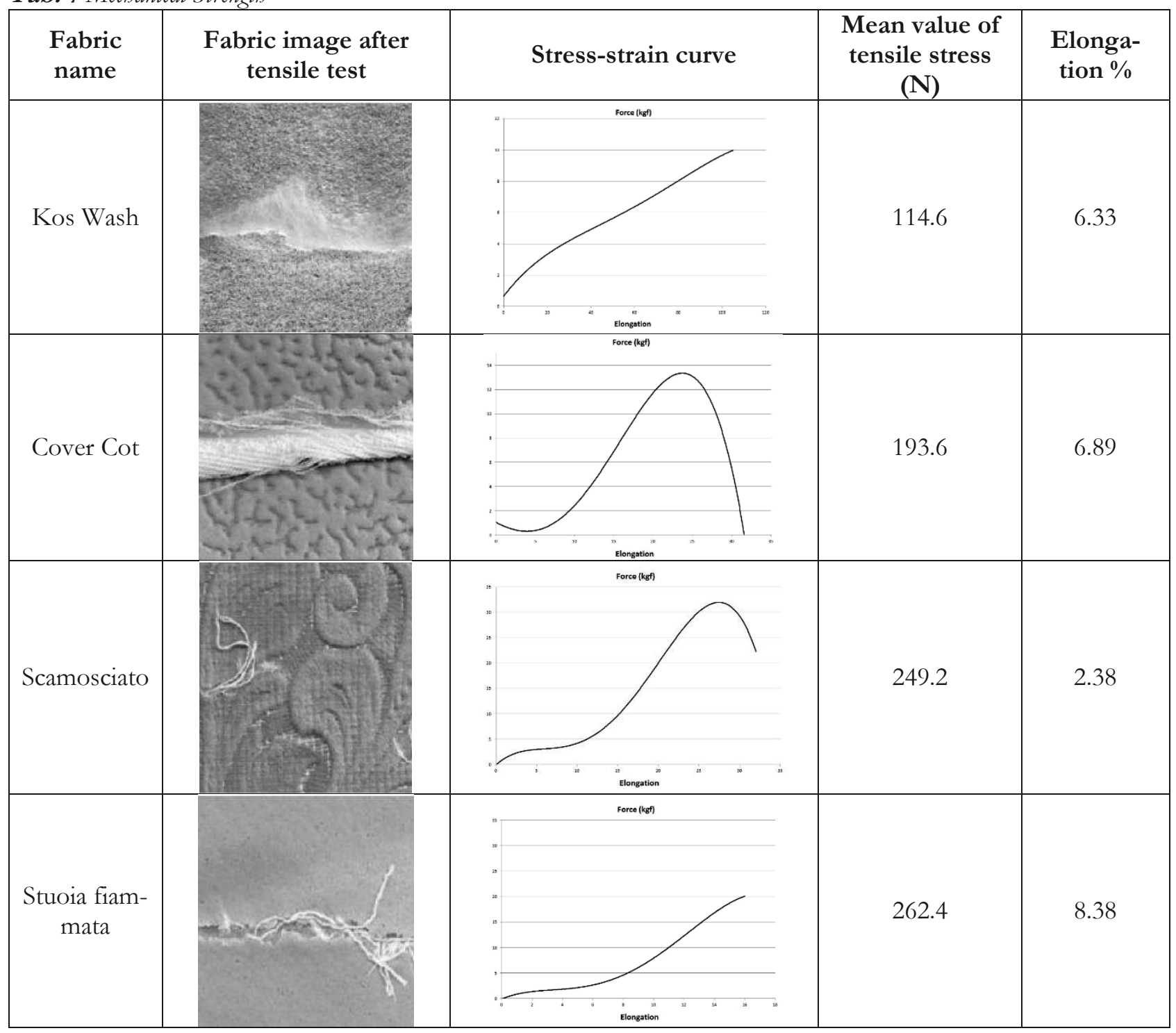

\section{References}

[1] BIDOKI, S.M., WITTLINGER, R. (2009). Waterborne Polyurethane Coating and its New Applications in Plush Finishing. Textile Research Journal, 2009, vol. 79, No. 8, 687-693. doi:10.1177/0040517508092020.

[2] YESILALAN, H.E., WARNER, S.B., LAOULACHE R. (2010). Penetration of Blade-Applied Viscous Coatings into Yarns in a Woven Fabric. Textile Research Joumal. 2010, vol. 80, No. 18, 1930-1941. doi:10.1177/0040517510371862.

[3] MENG, Q.B., LEE, S., NAH, C., LEE, Y.S. (2009). Preparation of waterborne polyurethanes using an amphiphilic diol for breathable waterproof textile coatings. Progress in Organic Coatings. 2009, vol. 66, No. 4, 382-386. doi: 10.1016/j.porgcoat.2009.08.016.

[4] ABDOLLAHI, S., FALLAH, N., DAVARPANAH, L. (2020). Treatment of real artificial leather manufacturing wastewater containing Dimethylamine (DMA) by photocatalytic method. Chemical Papers, 2020. vol. 74, 42034212. doi: 10.1007/s11696-020-01235-w.

[5] Kim, T. H., Kim, S. G. (2011). Clinical outcomes of occupational exposure to $\mathrm{n}, \mathrm{n}$-dimethylformamide: perspectives from experimental toxicology. Safety and health at work, 2011. vol. 2, No. 2, 97-104. doi: 10.5491/SHAW.2011.2.2.97. 
[6] Official Journal of the European Union, European Council Directive 2019/2020 of 20 June 2019.

[7] Regulation (EU) 2019/1020 of the European Parliament and of the Council of 20 June 2019 on market surveillance and compliance of products and amending Directive 2004/42/EC and Regulations (EC) No 765/2008 and (EU) No 305/2011.

[8] DURANTE, A. J., ZIMMERMAN, B. (1975). Mechanically Frothed Urethane Foam in Simulated Leather Composites: A Review of Coated Fabric Technology and the Requirements for Foam Composites. Journal of Coated Fabrics, 1975. vol 5, No. 2, 124-132. doi: $10.1177 / 009346587500500205$.

[9] ISO 105-B02:1994 Textiles - Tests for colour fastness - Part B02: Colour fastness to artificial light: Xenon arc. fading lamp test

[10] ISO 105-E04:1994 Textiles - Tests for colour fastness - Part E04: Colour fastness to perspiration.

[11] ISO 105-C10:2006 Textiles - Tests for colour fastness - Part C10: Colour fastness to washing with soap or soap. and soda

[12] ISO 105-X12:2016 Textiles - Tests for colour fastness - Part X12: Colour fastness to rubbing.

[13] ISO 105-E01:1994 Textiles - Tests for colour fastness - Part E01: Colour fastness to water.

[14] ISO 5085-1:1989 Textiles - Determination of thermal resistance.

[15] ISO 6330:2012(en) Textiles - Domestic washing and drying procedures for textile testing.

[16] ISO 12947-2:2016 Textiles - Determination of the abrasion resistance of fabrics by the Martindale method - Part 2: Determination of specimen breakdown.

[17] ASTM D5034 standard ASTM D5034 09(2017) Standard Test Method for Breaking Strength and Elongation of Textile Fabrics (Grab Test).
[18] HORMAIZTEGUI, M. E. V., DAGA, B., ARANGUREN, M. I., MUCCI, V. (2020). Biobased waterborne polyurethanes reinforced with cellulose nanocrystals as coating films. Progress in Organic Coatings, 2020, vol. 144, No. 105649. doi: 10.1016/j.porgcoat.2020.105649.

[19] https://www.brenntag.com, last accessed 08/02/2021.

[20] FURFERI, R., MANTELLASSI, F., VOLPE, Y. (2020). Design and manufacturing of an innovative triple-layer thermo-insulated fabric, Applied Sciences (Switzerland), 2020, vol. 10, No. 2 art. no. 680. doi: 10.3390/app10020680.

[21] HERMAN, A., KUBELKOVÁ, I., VRÁTNÝ, O., BEDNÁŘ, B. (2019). Influence of manufacture process parameters on dimensional stability of small blade castings, Manufacturing Technology, 2019, vol. 19, No. 1. doi: 10.21062/ujep/243.2019/a/1213$2489 / \mathrm{mt} / 19 / 1 / 49$.

[22] BRANCA, P. A., HUBIS, D. E., BUERGER, W., RUDOLF, C., TILLMANNS, R. (1998). U.S. Patent No. 5,814,405. Washington, DC: U.S. Patent and Trademark Office.

[23] MÜLLER M, RUGGIERO A, VALÁŠEK P. (2017). Mechanical Characterisation of Metal/Polymeric Composite Waste/Metal Sandwich Panel. Manufacturing Technology, 2017, vol. 17, No. 4, 530-536. doi: 10.21062/ujep/x.2017/a/12132489/MT/17/4/530.

[24] FURFERI, R., GOVERNI, L. (2008). The recycling of wool clothes: an artificial neural network colour classification tool. International Journal of Advanced Manufacturing Technology, 2008. vol. 37, 722-731. doi: 10.1007/s00170-0071011-2.

[25] SUCHÁNEK, A., LOULOVÁ, M., HARUŠINEC, J., STRÁŽOVEC, P. (2018). Use of infrared thermography under laboratory conditions. Manufacturing Technology, 2018. vol. 18 (3), 518-522. doi: 10.21062/ujep/131.2018/a/12132489/MT/18/3/518. 